Vol. 4 No. 2, 2020

ISSN (online): $2614-6614$

Available online at https://ejournal.unib.ac.id/index.php/korpus/index doi: https://doi.org/10.33369/jik.v4i2.8022

\title{
FEMINISME SOSIALIS DI DALAM NOVEL MENCARI PEREMPUAN YANG HILANG KARYA IMAD ZAKI
}

\author{
Andestend \\ Universitas Negeri Jakarta. Jl. Rawamangun Muka, RT.11/RW.14, \\ Rawamangun, Pulo Gadung, Jakarta Timur, daerah khusus Jakarta 13220 \\ Korespondensi: andestend@gmail.com
}

Abstrak

Tujuan penelitian ini untuk melihat feminisme sosialis yang terdapat di dalam novel Mencari Perempuan yang Hilang Karya Imad Zaki (diterjemahkan oleh Zuryati). Penelitian ini penelitian kualitatif dengan studi pustaka jadi tidak terikat oleh tempat penelitian. Data penelitian ini adalah feminis sosialis dalam novel Mencari Perempuan yang Hilang karya Imad Zaki. Sumber data penelitian ini adalah novel Mencari Perempuan yang Hilang karya Imad Zaki. Teknik pengumpulan data dilakukan dengan cara teknik catat. Teknik analisis data (1) membaca keseluruhan novel, (2) menandai dan mencatat kutipan pada novel, (3) mengklasifikasikan hasil temuan, (4) menganalisis hasil temuan sesuai dengan masalah penelitian, (5) langkah yang terakhir menyimpulkan. Hasil penelitian menunjukkan adanya feminisme sosialis di dalam Novel Mencari Perempuan Yang Hilang Krya Iamd Zaki yang Diterjemahkan Oleh Zuryati.

Kata kunci: feminisme sosialis, novel.

\begin{abstract}
The purpose of this study is to see the socialist feminism contained in the novel Looking for Missing Women by Imad Zaki (translated by Zuryati). This research is qualitative research with literature study so it is not bound by the place of research. The data of this study are socialist feminists in the novel Seeking Missing Women by Imad Zaki. The source of this research data is a novel Looking for a Missing Woman by Imad Zaki. Data collection techniques are carried out by means of notetaking techniques. Data analysis techniques (1) read the whole novel, (2) mark and record quotes on novels, (3) classify findings, (4) analyze findings according to research problems, (5) the final steps concluded. The results of the study show that there is socialist feminism in the novel seeking a lost woman, Iamd Zaki, translated by Zuryati.
\end{abstract}

Keywords: socialist feminism, novel 


\section{Andestend}

\section{PENDAHULUAN}

Karya sastra hadir sebagai wujud nyata imajinatif kreatif seorang sastrawan dengan proses yang berbeda antara pengarang yang satu dengan pengarang yang lain, terutama dalam penciptaan cerita fiksi. Proses tersebut bersifat individualis artinya cara yang digunakan oleh tiap-tiap pengarang dapat berbeda. Perbedaan itu meliputi beberapa hal diantaranya metode, munculnya proses kreatif dan cara mengekspresikan apa yang ada dalam diri pengarang hingga bahasa penyampaian yang digunakan.

Sastra sebagai hasil pekerjaan seni kreasi manusia tidak akan pernah lepas dari bahasa yang merupakan media utama dalam karya sastra. Sastra dan manusia erat kaitannya karena pada dasarnya keberadaan sastra sering bermula dari persoalan dan permasalahan yang ada pada manusia dan lingkungannya. Kemudian dengan adanya imajinasi yang tinggi seorang pengarang tinggal menuangkan masalah-masalah yang ada di sekitarnya menjadi sebuah karya sastra. Ditinjau dari segi isi, sastra biasanya dikatakan sebagai karangan yang tidak mengandung fakta tetapi fiksi. Sastra dibedakan dari berbagai jenis tulisan lain seperti, berita, laporan perjalanan, sejarah, biografi, dan tesis, sebab jenisjenis tulisan itu menyampaikan informasi yang berupa fakta. Dengan demikian menurut pandangan ini, jelas bahwa sastra adalah segala jenis karangan yang berisi dunia khayalan manusia, yang tidak bisa begitu saja dihubung-hubungkan dengan kenyataan.

Konsekuensi pandangan ini adalah bahwa dunia diciptakan sastrawan dalam puisi, novel, dan drama merupakan hasil khayalan yang harus dipisahkan dari dunia nyata, yakni dunia yang kita hayati sehari-hari ini. Salah satu bentuk karya sastra yang banyak digemari oleh pembaca adalah novel. Hal ini dapat dilihat dari perkembangan novel di Indonesia sekarang cukup pesat, terbukti dengan banyaknya novel-novel baru telah diterbitkan. Novel tersebut mempunyai bermacam tema dan isi, antara lain tentang problem-problem sosial yang pada umumnya terjadi dalam masyarakat, termasuk yang berhubungan dengan wanita sosok wanita sangatlah menarik untuk dibicarakan, wanita di sekitar publik cenderung dimanfaatkan oleh kaum laki-laki untuk memuaskan koloninya. Wanita telah menjelma menjadi bahan eksploitasi bisnis dan seks. Dengan kata lain, saat ini telah hilang sifat feminis yang dibanggakan dan disanjung bukan saja oleh wanita, tetapi juga kaum laki-laki.

Mary Wollstonecraft, feminis pertama yang mengatakan adanya pembodohan terhadap perempuan yang disebabkan tradisi masyarakat yang menjadikan perempuan sebagai makhluk yang tersubordinasi. Abad ke-20 (1949): lahir karya Simone De Beauvoir "le deuxieme sexe", ditemukan istilah kesetaraan. tahun 1960an : mulai menggunakan istilah penindasan dan pembebasan. Tahun 60-70an : membawa perubahan sosial yang luar biasa di dunia barat (lahirnya undang-undang yang menguntungkan perempuan), konsep patriarki mulai mengemuka. Tahun 70-80an: wacana feminisme bermunculan di Amerika latin, Asia, dan di negara-negara dunia ketiga pada umumnya, (Sauer, 2017).

Feminisme adalah sebuah pendekatan politik dan bisa menyerang pendekatan lain untuk asumsi mereka yang salah tentang wanita. Seperti yang dimiliki Judith Fetterly, terus terang menunjukkan, "Sastra adalah politik," dan politiknya "adalah laki-laki, (Guerin, 2005).

Pendekatan feminisme dalam kajian sastra sering dikenal dengan kritik sastra feminisme. Feminis menurut Nyoman Kutha Ratna (2005: 226) berasal dari kata femme yang berarti perempuan. Sugihastuti (2002:18) berpendapat bahwa feminisme adalah gerakan persamaan antara laki-laki dan perempuan di segala bidang baik politik, ekonomi, 
pendidikan, sosial dan kegiatan terorganisasi yang mempertahankan hak-hak serta kepentingan perempuan. Feminisme juga menurut Sugihastuti merupakan kesadaran akan penindasan dan pemerasan terhadap perempuan dalam masyarakat, baik di tempat kerja dan rumah tangga.

Dari berbagai pendapat tentang feminisme di atas telah banyak penelitian tentang ide feminisme di dalam karya sastra terutama dalam novel, penelitian yang pertama dilakukan oleh (Abidah, Khalieqy, Kelayakannya, \& Fuad, 2015) dengan judul Feminisme Dalam Novel Perempuan Berkalung Sorban Karya Abidah El Khalieqy Dan Kelayakannya hasilnya jenis aliran feminisme, novel Perempuan Berkalung Sorban dapat digolongkan sebagai salah satu novel beraliran feminisme radikal, jenis kritik feminisme, novel Perempuan Berkalung Sorban dapat digolongkan sebagai kritik feminis marxis/sosialis.

Selanjutnya penelitian yang dilakukan (Kurnia, 2013) dengan judul Kajian Feminisme Dalam Novel Secuil Hati Wanita Di Teluk Edenkarya Vanny Chrisma W. Dengan hasil 1) Bentuk ketidakadilan gender tokoh utama dalam novel Secuil Hati Wanita di Teluk Eden karya Vanny Chrisma W. berupa stereotipe (pelabelan negatif), kekerasan yang meliputi kekerasan domestik (kekerasan fisik dan kekerasan emosional), dan kekerasan publik. 2) Bentuk perjuangan tokoh utama untuk melawan penindasan dalam novel Secuil Hati Wanita di Teluk Eden karya Vanny Chrisma W. berupa pemberian pemahaman dan mengutarakan pendapat. Penelitian yang dilakukan oleh (Latif, 2006) membahasa tentang Analisis Kritik Sastra Arab Karya Nawal El-Sa'dawi. (Indayani, 2014) dengan judul Feminisme Dalam Novel Bibir Merah Karya Achmad Munif. Penelitian (Nursida, 2015) dengan judul Isu Gender Dan Sastra Feminis Dalam Karya Sastra Arab, dan masih banyak lagi penelitian tentang feminisme.

Berdasarkan uraian dan hasil penelitian di atas maka penulis ingin melihat feminisme sosialis yang terdapat di dalam novel Mencari Perempuan yang Hilang Karya Imad Zaki (diterjemahkan oleh Zuryati).

Pergerakan paling awal ditemui sejak abad ke-15 (Christine De Pizan menulis ketidakadilan yang dialami perempuan). Tahun 1800-an : MRPK pergerakan yang cukup signifikan (Susan dan Elizabeth telah memperjuangkan hak-hak politik, yaitu hak untuk memilih). tahun 1759-1797: menggunakan kata-kata "hak" ( Mary Wollstonecraft, feminis pertama yang mengatakan adanya pembodohan terhadap perempuan yang disebabkan tradisi masyarakat yang menjadikan perempuan sebagai makhluk yang tersubordinasi. Abad ke-20 (1949): lahir karya Simone De Beauvoir "le deuxieme sexe", ditemukan istilah kesetaraan. tahun 1960an : mulai menggunakan istilah penindasan dan pembebasan. Tahun 60-70an : membawa perubahan sosial yang luar biasa di dunia barat (lahirnya undang-undang yang menguntungkan perempuan), konsep patriarki mulai mengemuka. Tahun 70-80an: wacana feminisme bermunculan di Amerika Latin, Asia, dan di negara-negara dunia ketiga pada umumnya.

Feminisme adalah sebuah pendekatan politik dan bisa menyerang pendekatan lain untuk asumsi mereka yang salah tentang wanita. Seperti yang dimiliki Judith Fetterly, terus terang menunjukkan, "Sastra adalah politik," dan politiknya "adalah laki-laki, (Guerin, 2005).

Pendekatan feminisme dalam kajian sastra sering dikenal dengan kritik sastra feminisme. Feminis menurut Ratna (2005) berasal dari kata femme yang berarti perempuan. Sugihastuti dan Suharto berpendapat bahwa feminisme adalah gerakan 
persamaan antara laki-laki dan perempuan di segala bidang baik politik, ekonomi, pendidikan, sosial dan kegiatan terorganisasi yang mempertahankan hak-hak serta kepentingan perempuan. Feminisme juga menurut Sugihastuti merupakan kesadaran akan penindasan dan pemerasan terhadap perempuan dalam masyarakat, baik di tempat kerja dan rumah tangga. (Sugihastuti dan Suharto, 2005: 6).

Secara khusus, Spivak menantang klaim universal feminisme berbicara untuk semua wanita. Bersama dengan pemikir feminis postcolonial Chandra Talpade Mohanty, Rajeswari Sunder Rajan, Nawal El Saadawi dan Kumari Jayawardena, Spivak telah menghasilkan pemikiran ulang yang penting pemikiran feminis. Pemikiran ulang seperti itu telah menantang asumsi semua wanita adalah sama, dan menekankan pentingnya menghormati perbedaan ras, kelas, agama, kewarganegaraan dan budaya antara perempuan. Ini bukan untuk menunjukkan bahwa Spivak hanya menentang feminisme, atau bahwa Spivak adalah anti-feminis. Sebaliknya, Spivak gigih kritik terhadap pemikiran feminis barat bertujuan untuk memperkuat argumen dan klaim politik mendesak pemikiran feminis. (Sauer, 2017).

Kategori Feminis

- Feminisme Liberal

Menurut Fakih asumsi dasar feminisme liberal berakar pada pandangan bahwa kebebasan (freedom) dan kesamaan (equality) berakar pada rasionalitas dan pemisahan antara dunia privat dan publik. Feminisme ini berusaha memperjuangkan agar perempuan mencapai persamaan hak-hak yang legal secara sosial dan politik. Mampu membawa kesetaraan bagi perempuan dalam semua instansi publik untuk memperluas penciptaan pengetahuan bagi perempuan agar isu-isu tentang perempuan tidak lagi diabaikan.

- Feminisme Radikal

Menurut Bhasin (dalam Sugihastuti dan Itsna Hadi Saptiawan, 2007) feminisme radikal menganggap bahwa perbedaan gender bisa dijelaskan melalui perbedaan biologis atau psikologis antara laki-laki dan perempuan. Menurut aliran ini kekuasaan laki-laki atas perempuan, yang didasarkan pada pemilikan dan kontrol kaum laki-laki atas kapasitas reproduksi perempuan telah menyebabkan penindasan pada perempuan. Hal ini mengakibatkan ketergantungan perempuan secara fisik dan psikologis kepada laki-laki.

Feminisme radikal bertumpu pada pandangan bahwa penindasan terhadap perempuan terjadi akibat sistem patriarki. Tubuh perempuan merupakan objek utama penindasan oleh kekuasaan laki-laki. Oleh karena itu, feminisme radikal mempermasalahkan antara lain tubuh serta hak-hak reproduksi, seksualitas (termasuk lesbianisme), sekisme, relasi kuasa perempuan dan laki-laki, dan dikotomi domestikpublik. Pendekatan feminis radikal lebih menekankan bahwa ketimpangan hubungan gender bersumber pada perbedaan biologis. Perempuan memiliki kebebasan untuk memutuskan kapan ia harus menggunakan atau tidak menggunakan teknologi pengendali reproduksi (kontrasepsi, sterilisasi, aborsi) dan teknologi pembentuk reproduksi.

- Feminisme Marxis

Kelompok ini menolak keyakinan kaum feminis radikal yang menyatakan biologis sebagai dasar pembedaan gender. Bagi kaum ini penindasan perempuan adalah bagian 
dari penindasan kelas dalam hubungan produksi (Fakih, 2007). Persoalan perempuan selalu diletakkan dalam kerangka kritis atas kapitalisme.

Menurut Marx (dalam Sugihastuti, 2007) hubungan antara suami dan istri serupa dengan hubungan antara proletar dan borjuis. Bahkan kaum perempuan menurut pandangan kapitalis, dianggap bermanfaat bagi sistemnya karena reproduksi buruh murah. Pendekatan feminis marxis menjelaskan bahwa ketimpangan gender terjadi karena kapitalisme. Kapitalisme adalah tatanan sosial dimana para pemilik modal mengungguli kaum buruh dan laki-laki mengungguli perempuan.

- Feminisme Sosialis

Aliran ini menganggap bahwa konstruksi sosial sebagai sumber ketidakadilan terhadap perempuan. Termasuk di dalamnya adalah stereotip-stereotip yang dilekatkan pada kaum perempuan. Menurut Fakih (2007) penindasan perempuan terjadi di kelas manapun, bahkan revolusi sosialis ternyata tidak serta merta menaikkan posisi perempuan.

Bentuk Feminisme yang ketiga yang terjadi di dalam Novel ini ialah Feminisme Sosialisme. Feminisme ini terjadi pada kehidupan Ahlam dan juga kehidupan Nura, akan tetapi dalam bentuk pergerakan yang sangat berbeda. Feminisme ini bertujuan mengadakan restrukturisasi masyarakat agar tercapai kesetaraan gender. Ketimpangan gender disebabkan oleh sistem kapitalisme yang menimbulkan kelas-kelas dan division of labour, termasuk di dalam keluarga. Gerakan kelompok ini mengadopsi teori praxis Marxisme, yaitu teori penyadaran pada kelompok tertindas, agar kaum perempuan sadar bahwa mereka merupakan 'kelas' yang tidak diuntungkan. Proses penyadaran ini adalah usaha untuk membangkitkan rasa emosi para perempuan agar bangkit untuk mengubah keadaan (Megawangi, 1999).

- Feminisme Moderat

Feminisme ini menurut Waluyo (1998) memandang bahwa kodrat perempuan dan laki-laki memang berbeda, yang harus dibuat sama adalah hak, kesempatan, dan perlakuan. Karena itu yang penting adalah adanya hubungan yang sejajar antara perempuan dan laki-laki. Kemitrasejajaran ini merupakan pandangan pokok dari gender.

Karya sastra dapat disebut berperspektif feminis jika karya itu mempertanyakan relasi gender yang timpang dan memproniosikan terciptanya tatanan sosial yang lebih seimbang antara perempuan dan laki-laki. Tetapi tidak semua teks tentang perempuan adalah teks feminis. Demikian juga analisis tentang penulis perempuan tidak selalu bersifat feminis jika ia tidak mempertanyakan proses penulisan yang berkenaan dengan relasi gender dan perombakan tatanan sosial. https://pusatbahasaalazhar.wordpress.com/pesona-puisi/kritik-sastra-feminisme/ di akses 16 Mei 2019.

\section{METODE}

Penelitian ini menggunakan pendekatan kualitatif. Penelitian kualitatif adalah sebuah langkah pengumpulan data, kemudian dilanjutkan dengan analisis, serta interpretasi dari data narasi dan visual yang komprehensif (yaitu, bukan angka) untuk mendapatkan wawasan ke dalam fenomena tertentu yang menarik. Yang ditekankan dalam penelitian 


\section{Andestend}

kualitatif ini adalah bukan angka-angka atau tidak bersifat hitungan, (Lorraine R. Gay, Geoffrey E. Mills, 2003).

Penelitian ini penelitian kualitatif dengan studi pustaka jadi tidak terikat oleh tempat penelitian. Penelitian ini dilaksanakan pada bulan Juni 2019. Data penelitian ini adalah ide feminisme sosialis dalam novel Mencari Perempuan yang Hilang karya Imad Zaki. Sumber data penelitian ini adalah novel Mencari Perempuan yang Hilang karya Imad Zaki. Data adalah sebuah novel Mencari Perempuan yang Hilang karya Imad Zaki. Teknik pengumpulan data dilakukan dengan cara teknik catat. Teknik analisis data (1) membaca keseluruhan novel, (2) menandai dan mencatat kutipan pada novel, (3) mengklasifikasikan hasil temuan, (4) menganalisis hasil temuan sesuai dengan masalah penelitian, (5) langkah yang terakhir menyimpulkan.

\section{HASIL DAN PEMBAHASAN}

Bentuk Feminisme yang ketiga yang terjadi di dalam Novel ini ialah Feminisme Sosialisme. Feminisme ini terjadi pada kehidupan Ahlam dan juga kehidupan Nura, akan tetapi dalam bentuk pergerakan yang sangat berbeda. Feminisme ini bertujuan mengadakan restrukturisasi masyarakat agar tercapai kesetaraan gender. Ketimpangan gender disebabkan oleh sistem kapitalisme yang menimbulkan kelas-kelas dan division of labour, termasuk di dalam keluarga. Gerakan kelompok ini mengadopsi teori praxis Marxisme, yaitu teori penyadaran pada kelompok tertindas, agar kaum perempuan sadar bahwa mereka merupakan 'kelas' yang tidak diuntungkan. Proses penyadaran ini adalah usaha untuk membangkitkan rasa emosi para perempuan agar bangkit untuk mengubah keadaan (Megawangi, 1999).

Aliran ini menganggap bahwa konstruksi sosial sebagai sumber ketidakadilan terhadap perempuan. Termasuk di dalamnya adalah stereotip-stereotip yang dilekatkan pada kaum perempuan. Menurut Fakih (2007) penindasan perempuan terjadi di kelas manapun, bahkan revolusi sosialis ternyata tidak serta merta menaikkan posisi perempuan. Berikut ini temuan dan pembahasan feminisme sosial yang terdapat di dalam novel Mencari Perempuan Yang Hilang Karya Imad Zaki Yang Diterjemahkan Oleh Zuryati:

Pada pekerjaan dan pengabdiannya pada masyarakat, Ahlam berani mengambil risiko sebagai satu-satunya dokter bedah dan kemungkinan besar, profesi yang dia ambil juga jarang diambil oleh para wanita lainnya. Dia melawan rasa wanitanya yang lebih lemah daripada laki-laki untuk membuktikan kalau perempuan juga bisa melakukan pekerjaan yang seperti laki-laki. Dan juga dia melakukan pekerjaan tersebut karena panggilan kemanusiaan.

Hal tersebut tercermin dalam novel sebagai berikut:

"Satu lagi jantung anak berhenti seketika. Bertambah lagi korban meninggal di tangan kami. Kami hanya bisa menyaksikan dengan rasa pilu. Aham pun jatuh pingsan menghadapi peristiwa yang memukul jiwanya. Ablam adalah satu- satunya dokter perempuan yang bertugas di ruang operasi. Beberapa saat kemudian, setelah mendapat pertolongan perawat, Dokter Ablam sadar. Dikumpulkannya segala kekuatan dan semangatnya, lalu dia mencuci muka dan kembali bergabung bersama kamu untuk menolong anak-anak yang terluka parab". (Zaki:103) 
Dari pernyataan di atas, jelaslah bahwa kaum wanita bisa juga bergabung dengan dokter-dokter laki-laki. Sebagaimana dalam realita yang ada, kebanyakan dokter-dokter bedah yang ada di rumah sakit terdiri dari dokter-dokter laki-laki. Jarang sekali terlihat dokter wanita berada di sebuah ruang operasi. Hal ini disebabkan banyak sekali kelemahan wanita apabila berhubungan dengan darah; banyak sekali kaum wanita merasa takut apabila melihat darah, tubuh yang terluka, bagian tubuh yang disayat, dan lain sebagainya. Akan tetapi, Ahlam di sini berani melawan rasa kewanitaannya untuk rasa sosialnya.

Ahlam menuduh bahwa film- film akan membuat masyarakat Arab mempunyai ketergantungan, dan bahkan tidak akan beranjak dari muka televisi. Hal tersebut terlihat pada bagian di bawah ini:

Ahlam bangkit, marah, dan berkata, "Sudah! Pergi kalian, wahai tuan-tuan! Baik sinetron maupun film tidak akan membuat anak-anak mati sebagai korban. (Zaki:114)

Ahlam merasakan kejahatan ayahnya kepada manusia lain sehingga Ahlam pun merasa malu. Inilah awal dari gerakan Feminisme di dalam diri Ahlam. Pernyataan tersebut bisa dilihat sebagaimana berikut:

"Kekejaman yang paling sadis adalah bila kita bertengkar dengan orang yang kita cintai. Coba kau bayangkan dalam imajinasimu potret yang indah untuk seorang insan yang mulia dinodai oleh kehidupan yang kotor sehingga potret yang indah itu berubah menjadi percikanpercikan lumpur hitam. Bagaimana perasaanmu seandainya insan yang terhormat itu adalah primadonamu? Bagaimana kalau dia adalah ayahmu sendiri?” (Zaki:132)

Gerakan yang dilakukan oleh Ahlam ialah gerakan dimana dia sangat menginginkan keluarga yang sangat saling menyayangi. Akan tetapi, potret tersebut tidak terlihat di dalam keluarganya karena orang tuanya sering berkelahi mempertahankan pendapatnya masing-masing). Sebagai akibatnya, banyak hal- hal yang tidak pernah tuntas. Bahkan, Ahlam sendiri berani menentang ayahnya sendiri kalau ayahnya tidak menyetujui keinginannya untuk menikah dengan dokter Sholeh. Dia juga berani untuk keluar dari keluarganya. Hal tersebut bisa terlihat pada kutipan berikut:

"Bagaimana kalau ayahmu menolak mentab- mentab?"

Tiba- tiba rona wajah Ablam berubah. Dia tidak hendak bangkit dari tempat duduknya. Setelah beberapa saat terdiam dan berpikir, dia berkata sementara kedua matanya basab dengan air mata. "Sholeh, jia ayabku tidak menyetujui pernikahan kita, aku tidak akan pernah mencintai laki- laki lain untuk penggantimu." (Zaki:180)

Demi cinta, Ahlam berani mengambil risiko kalau dia juga tidak akan pernah mau mencintai laki-laki lain, yang ini juga berarti Ahlam tidak akan pernah menikah dengan lelaki mana pun. Ahlam mempunyai prinsip Feminisme dimana dia berani menentang hasrat kaum laki-laki, dalam hal ini ayahnya sendiri.

Hal ini lebih banyak terlihat pada Ibu Dokter Sholeh yang mengerti kegundahan hati anaknya karena perbedaan status anaknya dengan Dokter Ahlam. Bahkan, sang ibu rela menjual warisannya demi Sholeh bisa meminang Dokter Ahlam. Hal ini terlihat pada kutipan sebagai berikut ini: 


\section{Andestend}

"Kalau kau sungguh- sungguh mencintainya, aku rela menjual tanah warisan kakekmu. Hasil penjualan itu mungkin bisa membuat bidup Ablam layak bersamamu. Aku bangga dengan ibuku. Betapa besar perbedaan antara orang yang mengorbankan hartnya demi kebahagiaan anaknya dengan orang yang mengorbankan kebahagiaan anaknya demi harta yang dimilikinya. (Zaki: 226-227).

Wanita harus dapat melawan kejahatan-kejahatan yang timbul dari kaum laki- laki sehingga membuat kaum laki-laki menjadi berpikir untuk melakukan kejahatan seksualitas terhadap wanita. Di dalam novel itu sendiri, ketika Nura pergi ke kota, dia melihat kalau banyak kaum laki-laki bertindak seenaknya; kaum laki-laki berpikir kalau wanita tidak berhak untuk mengeluarkan apa yang ada dipikirkannya sebagaimana terlihat sebagai berikut:

"Ttu bakku. Aku bebas memutar lagu apa yang aku mau," katanya dengan marah. "Kau bebas kalau kau sendirian. Tapi kalau ada penumpang kau harus juga menghargai hake dan perasaan penumpang." "Kelibatannya kau gadis pemberani," balasnya sambil tertawa terbahak-bahak. "O... kecantikanmu rupanya tidak membuat orang terpikat." (Zaki: 279).

Kejadian di atas merupakan adu mulut antara Nura dengan sopir taksi yang mengantarkannya. Sang sopir menyangka kalau perempuan tidak bisa memprotes atau berbuat apa saja sehingga dia dengan seenaknya melakukan apa yang dia mau. Akan tetapi, Nura malah menghardiknya sehingga membuat sang sopir terkejut dengan keberanian Nura.

Pendidikan merupakan sebuah proses seseorang untuk mempunyai kematangan berpikir yang sangat diperlukan di dalam dunia pekerjaan. Sehingga, seorang perempuan feminisme sosialis menyatakan kalau wanita juga perlu mempunyai pendidikan yang sama seperti laki-laki. Dulu, hanya laki- laki yang bisa duduk di bangku pendidikan sampai perguruan tinggi. Akan tetapi, karena perjuangan kaum feminis, sekarang sudah banyak wanita yang mengecam pendidikan tinggi. Nura, sebagai wanita desa, mempunyai pikiran yang sangat kuat tentang pendidikan. Dia berpikir kalau wanita bodoh bisa diperdaya oleh kaum laki-laki. Oleh karena itu, cita-cita Nura berhasil mengantarkannya pada perguruan tinggi. Walaupun orang tua Nura tidak bisa membiayainya, akan tetapi dia juga bekerja sambil kuliah. Hal tersebut terlihat pada penjelasan sebagai berikut:

Gaji? Sangat menggiurkan. Aku bekerja dengan tekun dan ikhlas. Direktur menyuai pekerjaanku. Setiap libur musim panas aku dibawa kemana dia pergi. Satu hal yang kubanggakan dari dia adalah perhatiannya terhadap penyelesaian studiku. (Zaki: 284285)

Kaum feminisme lebih menekankan kepada perjuangannya untuk menuntut persamaan hak, seperti pendidikan, ekonomi, dan lain sebagainya. Feminisme ini terjadi sebagai akibat dari pelecehan-pelecehan kaum laki-laki terhadap perempuan seperti perempuan ialah makhluk yang lemah, perempuan hanya akan berujung pada sumur, kasur, dan kasur. Sebagai akibatnya, hak untuk pendidikan tidak bisa dilakukan terhadap kaum perempuan.

Seorang feminis sosialisme juga akan rela melakukan apa saja untuk memajukan kaumnya tanpa melihat jender. Seperti seseorang yang disangka Ahlam yang memberikan 
pertolongan medis gratis dan bahkan memerikan pengajaran baca tulis. Hal tersebut bisa terlihat pada novel sebagaimana berikut ini:

"Suatu hari beredar berita babwa di sebuah desa ada seorang dokter yang baik. Dia rela berkorban apa saja untuk. mengobati orang sampai desa- desa terpencil. Namanya Dokter Farida. Siang hari dia mengobati orang. Bila senja datang, dia mengumpulkan orang- orang buta buruf untuk diajari berbagai ilmu, khususnya membaca dan menulis”. (Zaki: 372)

Keberanian Nura bisa terlihat pada halaman sebagai berikut:

"Tidak kusangka sedikitpun bahwa aku sedang bekerja untuk. perusabaan yang menjual barang-barang yang sudah rusak dan berbahaya?!” Oh... apa yang harus kulakukan? Aku gugup. Aku pura-pura tidak mengerti, "Barang rusak? Hai Nona Nura! Kau bicara apa? "Kau membuat transaksi untuk barang- barang yang sudah kadaluwarsa? Kau berminat untuk mengimpornya?" (Zaki: 341)

Di sini Nura juga bahkan berani akan membongkar kasus tersebut kepada pihak yang berwajib tanpa melihat siapa dalang yang berada di belakang kejahatan ini. Hal ini menunjukkan kalau Nura tidak mempunyai rasa takut terhadap orang yang sangat kejam dan bengis. Di novel, pemikiran tersebut bisa dilihat pada kutipan berikut ini:

"Aku tidak peduli siapa yang menyuruh untuk membalas atau tidak membalas surat ini. Kenyataan yang pasti adalah aku sedang berhadapan dengan penjahat ulung yang tidak bisa didiamkan begitu saja. Akan aku laporkan pada yang berwajib," kata Nura. (Zaki:343)

Di samping keberanian Nura untuk membongkar kedok Abdul Ghani, ternyata Ahlam berani bersikap hal yang sama. Bahkan, orang yang dia adukan beserta bukti- bukti ialah bapaknya sendiri. Doktor Syarif yang merupakan seorang laki- laki juga tidak berani mengambil risiko, padahal Doktor Syarif mempunyai bukti yang lebih banyak. Kesaksian dari Ahlam bisa dilihat pada kutipan berikut ini:

"Saya mohon tuan hakim mendengarkan saya sampai selesai! Saya punya banyak bukti yang kuat. Bukti ini boleh jadi akan mengubah jalannya persidangan. Saya harap hadirin sekalian mendengarkan saya. Apa yang saya katakana ini sangat penting dan sangat berbahaya..." (Zaki:349)

Pendapat tersebut diperkuat dengan kesaksian Ahlam sebagai berikut: "Dengan menyebut nama Allah Yang Maha Besar saya bersumpah akan mengatakan kebenaran sepahit apapun. Akan saya katakana meski manusia menuduh saya, pengkhianat, bahkan gila." (Zaki:350)

Di sini terlihatlah pergerakan feminisme dimana Ahlam berani bersaksi tentang kejahatan ayahnya sendiri. Dia terpaksa mengorbankan ayahnya sendiri karena mengetahui akan bahaya yang akan terjadi pada negeri tersebut apabila ayahnya tidak segera ditangkap. Hal yang sangat jarang dilakukan di dunia nyata. Biasanya, seorang anak pasti akan membela anaknya sendiri walaupun tahu ayah mereka bersalah. Akan tetapi, Ahlam berani bersaksi atas nama Allah Tuhan semesta alam. Bahkan seorang anak lakilaki jarang yang berani melawan ayahnya sendiri. 


\section{PENUTUP}

Feminisme adalah sebuah gerakan yang dipelopori oleh kaum perempuan yang bertujuan untuk mendapatkan hak yang sama antara laki-laki dan perempuan, baik dalam bidang pendidikan, pekerjaan, sosial, ekonomi, dan lain-lain. Di dalam Novel yang di tulis Imad Zaki ini memberikan gambaran tentang ide feminisme sosialis, diantaranya ingin mendapatkan pendidikan yang tinggi, perempuan mampu bekerja seperti laki-laki dan bukan sekedar di kasur, dapur dan sumur.

\section{DAFTAR RUJUKAN}

Abidah, K., Khalieqy, E. L., Kelayakannya, D. A. N., \& Fuad, M. (2015). J-Simbol (Bahasa, Sastra, dan Pembelajarannya) Juni 2015. J-Simbol (Babasa, Sastra, Dan Pembelajarannya), 1-9.

Guerin, W. L. (2005). of Critical to Literature.

Indayani. (2014). Feminisme Dalam Novel Bibir Merah. Jurnal Buana Bastra, (1), 31-42.

Kurnia, I. (2013). Kajian Feminisme dalam Novel Secuil Hati Wanita di Teluk Eden Karya Vanny Chrisma W. Jurnal Pendidikan Dan Pembelajaran, 2(7), 11. Retrieved from http://jurnal.untan.ac.id/index.php/jpdpb/article/view/2376

Latif, H. M. N. (2006). Analisis kritik sastra arab karya nawal el-sa'dawi. 55-44, 5يدان بدلأ أ

Lorraine R. Gay, Geoffrey E. Mills, P. W. A.-E. R. C. for A. and A. (10th E.-P. (2011)-1. (2003). s3 Meredith D. Gall, Walter R. Borg, Joyce P. Gall-Educational Research_An Introduction (7th Edition)-Allyn \& Bacon (2003).pdf.

Nursida, I. (2015). Isu Gender Dan Sastra Feminis Dalam Karya Sastra Arab: Alfaz (Vol.3 No.1 [Januari-Juni] 2015 ISSN: 2339-2882) $\square \square \square \square \square$.

Ratna, Nyoman Kutha. 2007. Sastra dan Cultural Studies: Representasi Fiksi dan Fakta. Yogyakarta: Pustaka Belajar

Sugihastuti, dan Suharto. 2010. Kritik Sastra Feminis: Teori dan Aplikasi. Yogyakarta: Pustaka Belajar.

Sauer, E. (2017). The Postcolonial Critic. In South Asian Review (Vol. 30). https://doi.org/10.1080/02759527.2009.11932679

Zaki, Imad. 2002. Mencari Perempuan yang Hilang. Jakarta: Zikrul Hakim (diterjemahkan oleh Zuryati). 